\title{
Impact of cardiovascular risk factors on carotid intima-media thickness: sex differences
}

\author{
This article was published in the following Dove Press journal: \\ Clinical Interventions in Aging \\ 23 May 2016 \\ Number of times this article has been viewed
}

\author{
Maria Łoboz-Rudnicka' \\ Joanna Jaroch' \\ Zbigniew Bociąga' \\ Barbara Rzyczkowska' \\ Izabella Uchmanowicz ${ }^{2}$ \\ Jacek Polański ${ }^{3}$ \\ Krzysztof Dudek ${ }^{4}$ \\ Andrzej Szuba ${ }^{5}$ \\ Krystyna Łoboz-Grudzień ${ }^{2}$ \\ 'Department of Cardiology, \\ T. Marciniak Hospital, ${ }^{2}$ Public Health \\ Department, Wrocław Medical \\ University, ${ }^{3}$ Private Practice, $\mathrm{Na}$ \\ Biskupinie, Wrocław, ${ }^{4}$ Faculty of \\ Mechanical Engineering, Wrocław \\ University of Technology, ${ }^{5}$ Division \\ of Angiology, Wrocław Medical \\ University, Wrocław, Poland
}

Correspondence: Maria Łoboz-Rudnicka Department of Cardiology,T. Marciniak Hospital, ul. Fieldorfa 2, 50-996 Wrocław, Poland

Tel +48 517868585

Email marialoboz@o2.pl
Background and purpose: There has been growing interest in the sex-related differences in the impact of cardiovascular (CV) risk factors on carotid intima-media thickness (CIMT). Therefore, we aimed at examining the influence of CV risk factors on CIMT in men and women and identifying differences between males and females in the risk profiles affecting CIMT.

Patients and methods: The study group consisted of 256 patients (mean age 54.7 years), including 134 females (52\%), with the following CV risk factors: arterial hypertension, type 2 diabetes mellitus, dyslipidemia, nicotine addiction, overweight, and obesity. Subjects with the history of any overt CV disease were excluded. CIMT was measured through B-mode ultrasound examination of the right common carotid artery. In the analysis of CIMT values at different ages, the patients were divided into three age groups: 1) $<45$ years, 2) 45-60 years, and 3) $>60$ years. Regression analysis was used to examine the influence of CV risk factors on CIMT in men and women.

Results: CIMT increased with age in both men and women. Women had lower values of CIMT than men $(0.54 \mathrm{~mm}$ vs $0.60 \mathrm{~mm}, P=0.011)$. The analysis in three age subgroups revealed that CIMT values were comparable in men and women in group $1(0.48 \mathrm{~mm}$ vs $0.48 \mathrm{~mm}, P=0.861)$, but over the age of 45 years, CIMT values became significantly lower in women compared to men (group 2: $0.51 \mathrm{~mm}$ vs $0.63 \mathrm{~mm}, P=0.005$; group 3: $0.63 \mathrm{~mm}$ vs $0.72 \mathrm{~mm}, P=0.020$ ). Significant differences were observed between the sexes in terms of risk factor impact on CIMT. In men, only three factors significantly affected CIMT: age $(b=+0.009, P<0.0001)$, hypertension $(b=+0.067, P<0.05)$, and type 2 diabetes $(b=+0.073, P<0.05)$. In women, apart from age $(b=+0.008, P<0.0001)$ and type 2 diabetes $(b=+0.111, P<0.01)$, significant factors were pulse pressure (PP; $b=+0.005, P<0.0001)$, body mass index $(b=+0.007, P<0.05)$, increased waist circumference $(b=+0.092, P<0.01)$, and metabolic syndrome $(b=+0.071, P<0.05)$. In the multiple regression analysis, independent CIMT determinants for the entire group were age $(\beta=0.497$, $P<0.001)$ and body mass index $(\beta=0.195, P=0.006)$. For males, age was the only independent determinant of CIMT ( $\beta=0.669, P<0.001)$. For females, these were PP $(\beta=0.317, P=0.014)$, age $(\beta=0.242, P=0.03)$, and increased waist circumference $(\beta=0.207, P=0.048)$.

Conclusion: CIMT values are lower in women than in men, which is most pronounced over the age of 45 years. There are sex-related differences in the profile of $\mathrm{CV}$ risk factors affecting CIMT: in males, CIMT is mostly determined by age, while in females, by age, PP, and increased waist circumference.

Keywords: carotid intima media thickness, risk factors, sex differences

\section{Background}

Recently, there has been a growing interest in the impact of sex differences on the structure and function of vascular tree. Some data indicate that age-related changes in the cardiovascular system occur differently in males and females. 
As carotid intima-media thickness (CIMT) has proven to be a valuable predictor of myocardial infarction and ischemic stroke, independent of traditional risk factors, it is considered to be a marker of subclinical atherosclerosis. ${ }^{1-4}$ It is worth noting that this approach may be controversial, as a CIMT increase, especially in the initial stages, results mainly from the thickening of the carotid media and may occur with aging without concomitant formation of atherosclerotic plaques. ${ }^{5}$ The role of age and shear stress caused by hemodynamic factors such as blood pressure components and tachycardia is also emphasized. ${ }^{6}$ Recent large metaanalyses gave rise to controversies regarding the impact of traditional cardiovascular (CV) risk factors on CIMT and the predictive value of CIMT. ${ }^{6-9}$

The distinct impact of risk factors on the development of atherosclerosis and cardiovascular disease (CVD) in women and men is being debated. The INTERHEART study provided evidence for sex-related differences in the profile of risk factors associated with myocardial infarction and showed that diabetes and hypertension increase the risk of coronary disease more in women than in men. ${ }^{10}$ Little is known about specific impact of traditional CV risk factors on CIMT in relation to sex. Therefore, we aimed to identify differences between male and female risk factor profiles affecting CIMT.

\section{Aim of the study}

The aim of the study was 1) to assess the changes of CIMT values occurring with age in women and men, 2) to evaluate the impact of CV risk factors on CIMT in women and men, and 3 ) to identify differences between the sexes in terms of risk factor profiles.

\section{Patients and methods}

The study group consisted of 256 Caucasian patients (mean age 54.7 years), including 134 females (52\%), with the following $\mathrm{CV}$ risk factors: arterial hypertension, type 2 diabetes mellitus, dyslipidemia, nicotine addiction, overweight, and obesity. Exclusion criteria were as follows: 1) history of any overt CV disease (ischemic heart disease, history of ischemic or hemorrhagic stroke, and lower extremity artery disease), 2) atherosclerotic plaque in a carotid artery detected by ultrasound, 3) signs of myocardial ischemia in the electrocardiography (ECG), and 4) impaired left ventricular ejection fraction, regional wall motion abnormalities, or significant valvular disease on echocardiography. The participants of the study were recruited by general practitioners, who were invited to refer subjects with $\mathrm{CV}$ risk factors (but without manifest $\mathrm{CV}$ disease) for the assessment in our outpatient clinic.
In the analysis of CIMT values at different ages, the patients were divided into three age groups: 1$)<45$ years, 2) 45-60 years, and 3) $>60$ years.

The hypertensive group included patients 1) previously diagnosed with hypertension, but untreated, and 2) newly diagnosed with hypertension. Hypertension was diagnosed if systolic blood pressure (SBP) $\geq 140 \mathrm{mmHg}$ and/or diastolic blood pressure (DBP) $\geq 90 \mathrm{mmHg}$ was found after a 15-minute rest during two separate visits (scheduled at an interval of at least 7 days). The type 2 diabetes group consisted of patients previously diagnosed with type 2 diabetes, including those treated with hypoglycemic agents.

Dyslipidemia was defined as 1) fasting low-density lipoprotein (LDL) cholesterol serum level $>115 \mathrm{mg} / \mathrm{dL}$, 2) fasting high-density lipoprotein (HDL) cholesterol serum level $<40 \mathrm{mg} / \mathrm{dL}$ for men and $<50 \mathrm{mg} / \mathrm{dL}$ for women, 3) fasting triglyceride serum level $>150 \mathrm{mg} / \mathrm{dL}$, or 4) treatment with hypolipidemic drugs.

Increased waist circumference was defined in accordance with European Society of Hypertension and European Society of Cardiology criteria, as a circumference of $\geq 88 \mathrm{~cm}$ for women and $\geq 102 \mathrm{~cm}$ for men. ${ }^{11}$

Body mass index (BMI, $\mathrm{kg} / \mathrm{m}^{2}$ ) was calculated as the quotient of body weight $(\mathrm{kg})$ to height squared $\left(\mathrm{m}^{2}\right)$.

The nicotine-addicted group included active smokers and those who had quit smoking within the previous 12 months.

Metabolic syndrome was defined in accordance with the National Education Cholesterol Program Adult Treatment Panel III criteria, revised in 2005. ${ }^{12}$

Patient histories were taken using questionnaires including questions on present and past diseases, hospitalization, and treatment.

The patients' body weight, height, and waist and hip circumferences were measured.

Laboratory blood tests were performed in the morning to determine fasting levels (participants were asked not to have eaten for at least 6 hours before sampling) of glucose, total cholesterol, LDL cholesterol, HDL cholesterol, triglycerides, and C-reactive protein.

All study participants provided informed written consent. The study was approved by Wrocław Medical University Research Ethics Committee.

\section{CIMT measurement}

CIMT was measured through B-mode ultrasound examination of the right common carotid artery with a linear probe operating at $>7 \mathrm{MHz}$. A longitudinal section of the right 
common carotid artery was obtained; then, three subsequent CIMT measurements were performed, $\sim 1 \mathrm{~cm}$ beneath the bifurcation, in the area devoid of plaques, on the distal wall of the right common carotid artery, using a semi-automated application. The procedure was performed in accordance with the Mannheim protocol. ${ }^{13}$

\section{Statistical methods}

Statistical analysis was performed using STATISTICA V 10 software and EXCEL spreadsheets. All quantitative parameters (eg, age, BMI, CIMT, SBP, and DBP) in all subgroups were tested for distribution normality using the Shapiro-Wilk test at a threshold significance level of $P<0.05$. Mean, SD, median values, lower and upper quartiles (Q1 and Q3) or interquartile ranges, and extremes values, minimum and maximum, were calculated for the quantitative parameters. For parameters with normal distributions and homogeneous variances, significance of differences between the mean values in the two groups was verified using Student's $t$-test. For parameters with distributions significantly different from normal or heterogeneous variances, significance of differences between the mean values in the two groups (eg, females vs males) was verified using the Mann-Whitney $U$-test, significance of differences between the mean values in the two dependent samples was verified using the Wilcoxon test, and significance of differences between the mean values in more than two groups (three age groups) was verified using the Kruskal-Wallis test. For nominal variables (sex, presence of symptoms, etc), numbers (n) and percentages (\%) were calculated and cross-tabulated. Hypotheses on the independence of nominal and ordinal characteristics were verified using Pearson's chi-squared test or Fisher's exact test. The strength of correlations between quantitative variables was determined using Spearman's rank correlation coefficient or Pearson's correlation coefficient (if variable distributions did not significantly differ from normal). For all tests, a significance threshold of $P<0.05$ was used.

\section{Results}

Participants' clinical characteristics are given in Table 1.

Mean age did not differ significantly between females and males $(55.7 \pm 9.9$ years vs $53.5 \pm 11.3$ years, respectively,

Table I Participants' characteristics

\begin{tabular}{|c|c|c|c|c|}
\hline & \multicolumn{4}{|c|}{ Participants } \\
\hline & $\begin{array}{l}\text { All } \\
(N=256)\end{array}$ & $\begin{array}{l}\text { Female (F) } \\
(n=134)\end{array}$ & $\begin{array}{l}\text { Male (M) } \\
(n=122)\end{array}$ & $\frac{F \text { vs } M}{P \text {-value }}$ \\
\hline Age (years) & $54.7 \pm 10.6$ & $55.7 \pm 9.9$ & $53.5 \pm 11.3$ & 0.099 \\
\hline BMI $\left(\mathrm{kg} / \mathrm{m}^{2}\right)$ & $28.6 \pm 4.5$ & $28.3 \pm 4.9$ & $29.0 \pm 3.9$ & 0.212 \\
\hline Waist circumference $(\mathrm{cm})$ & $95 \pm 14$ & $89 \pm 12$ & $103 \pm 11$ & $<0.001$ \\
\hline Hip circumference $(\mathrm{cm})$ & $108 \pm 9$ & $107 \pm 10$ & $108 \pm 8$ & 0.417 \\
\hline WHR & $0.89 \pm 0.09$ & $0.83 \pm 0.08$ & $0.95 \pm 0.07$ & $<0.001$ \\
\hline Number (percentage) of patients with hypertension & $160(65.8)$ & 78 (62.9) & $82(68.9)$ & 0.395 \\
\hline $\mathrm{SBP}(\mathrm{mmHg})$ & $134 \pm 18$ & $133 \pm 19$ & $135 \pm 16$ & 0.474 \\
\hline $\mathrm{DBP}(\mathrm{mmHg})$ & $76 \pm 11$ & $77 \pm 11$ & $75 \pm 10$ & 0.147 \\
\hline MAP (mmHg) & $95 \pm 12$ & $96 \pm 12$ & $95 \pm 11$ & 0.602 \\
\hline $\mathrm{PP}(\mathrm{mmHg})$ & $58 \pm 14$ & $56 \pm 16$ & $60 \pm 12$ & 0.048 \\
\hline $\mathrm{HR}(/ \min )$ & $70 \pm 10$ & $7 I \pm 10$ & $69 \pm 9$ & 0.074 \\
\hline Number (percentage) of patients with type 2 diabetes & $90(46.4)$ & $40(40.4)$ & $50(52.6)$ & 0.118 \\
\hline Glucose level $^{a}(\mathrm{mg} / \mathrm{dL})$ & $101 \pm 23$ & $100 \pm 21$ & $103 \pm 26$ & 0.393 \\
\hline Number (percentage) of patients with dyslipidemia & $195(81.6)$ & $103(88.0)$ & $92(75.4)$ & 0.019 \\
\hline Number (percentage) of patients with treated dyslipidemia & $3 \mid(\mid 5.9)$ & $16(15.5)$ & $15(16.3)$ & 0.961 \\
\hline TC levela $^{a}(\mathrm{mg} / \mathrm{dL})$ & $220 \pm 41$ & $225 \pm 43$ & $213 \pm 37$ & 0.016 \\
\hline LDL cholesterol level ${ }^{a}(\mathrm{mg} / \mathrm{dL})$ & $130 \pm 39$ & $130 \pm 43$ & $129 \pm 34$ & 0.858 \\
\hline HDL cholesterol level ${ }^{a}(\mathrm{mg} / \mathrm{dL})$ & $54 \pm 16$ & $60 \pm 18$ & $49 \pm 12$ & $<0.001$ \\
\hline TG level $^{a}(\mathrm{mg} / \mathrm{dL})$ & $154 \pm 97$ & $150 \pm 80$ & $159 \pm 112$ & 0.505 \\
\hline Number (percentage) of smokers & $94(36.7)$ & $45(33.6)$ & $49(40.2)$ & 0.174 \\
\hline CRP $(\mathrm{mg} / \mathrm{L})$ & $2.6 I \pm 3.74$ & $2.61 \pm 3.37$ & $2.62 \pm 4.27$ & 0.986 \\
\hline Number (percentage) of patients with metabolic syndrome & $119(46.5)$ & $61(45.5)$ & $58(47.5)$ & 0.843 \\
\hline LV ejection fraction \% & 70.4 & 70.6 & 70.0 & 0.250 \\
\hline
\end{tabular}

Notes: aMorning fasting serum concentration. Data presented as mean \pm SD or $\mathrm{n}(\%)$ parameter values. Data in bold indicates statistical significance.

Abbreviations: BMI, body mass index; WHR, waist-to-hip ratio; SBP, systolic blood pressure; DBP, diastolic blood pressure; MAP, mean arterial pressure; PP, pulse pressure; HR, heart rate; TC, total cholesterol; LDL, low-density lipoprotein; HDL, high-density lipoprotein; TG, triglycerides; CRP, C-reactive protein; LV, left ventricle. 
$P=0.099)$. Compared to male participants, female patients had lower values of the following anthropometric parameters: waist circumference $(89 \pm 12 \mathrm{~cm}$ vs $103 \pm 11 \mathrm{~cm}, P<0.001)$ and waist-to-hip ratio (WHR, $0.83 \pm 0.08$ vs $0.95 \pm 0.07$, $P<0.001)$. Mean pulse pressure (PP) was lower in women than in men $(56 \pm 16 \mathrm{mmHg}$ vs $60 \pm 12 \mathrm{mmHg}, P<0.001)$. The female subgroup had higher total cholesterol $(225 \pm 43 \mathrm{mg} / \mathrm{dL}$ vs $213 \pm 37 \mathrm{mg} / \mathrm{dL}, P=0.016)$ and HDL cholesterol levels $(60 \pm 18$ vs $49 \pm 12, P<0.001)$ and included a higher percentage of dyslipidemic patients ( $88 \%$ vs $75.4 \%, P=0.019)$ than the male subgroup.

The participants' clinical characteristics in the three age groups are presented in Table 2 . In each age group, the difference in most of the anthropometric parameters (waist circumference and WHR) and HDL cholesterol level between men and women was present. What is noteworthy is that the values of blood pressure components differentiated between men and women only in $<45$ years age group (SBP and PP were significantly lower and DBP was higher in women than in men). In $>60$ years age group, the blood pressure component had comparable values and dyslipidemia occurred more frequently in women than in men $(92.3 \%$ vs $70 \%, P=0.011)$, which was not observed in younger subjects.

\section{Common CIMT}

Median CIMT values for female and male subjects are given in Table 3. Trends in CIMT values in the age groups are shown in Figure 1.

Women had lower median CIMT than men $(P=0.011)$. In $<45$ years age group, median CIMT values were still similar ( $0.48 \mathrm{~mm}$ for female patients vs $0.48 \mathrm{~mm}$ for male patients, $P=0.861$ ), but at older ages, men had higher CIMT

Table 2 Participants' clinical characteristics in three age groups

\begin{tabular}{|c|c|c|c|c|c|c|c|c|c|}
\hline & \multicolumn{3}{|c|}{ Subjects $<\mathbf{4 5}$ years } & \multicolumn{3}{|c|}{ Subjects $45-60$ years } & \multicolumn{3}{|c|}{ Subjects $>60$ years } \\
\hline & Females & Males & F vs $M$ & Females & Males & F vs $M$ & Females & Males & F vs $\mathbf{M}$ \\
\hline & $(n=23)$ & $(n=50)$ & $P$-value & $(n=59)$ & $(n=55)$ & $P$-value & $(n=52)$ & $(n=40)$ & $P$-value \\
\hline Age (years) & $38.9 \pm 4.8$ & $36.9 \pm 5.5$ & 0.194 & $54.4 \pm 3.4$ & $53.3 \pm 4.1$ & 0.144 & $64.7 \pm 4.3$ & $65.0 \pm 5.0$ & 0.752 \\
\hline BMI $\left(\mathrm{kg} / \mathrm{m}^{2}\right)$ & $26.9 \pm 4.5$ & $29.1 \pm 3.8$ & 0.059 & $28.6 \pm 5.2$ & $29.2 \pm 4.1$ & 0.506 & $28.6 \pm 4.6$ & $28.6 \pm 3.8$ & 0.999 \\
\hline Waist circumference $(\mathrm{cm})$ & $87 \pm 13$ & $100 \pm 12$ & 0.002 & $89 \pm 12$ & $105 \pm 10$ & $<\mathbf{0 . 0 0 1}$ & $91 \pm 12$ & $103 \pm 12$ & $<\mathbf{0 . 0 0 1}$ \\
\hline Hip circumference $(\mathrm{cm})$ & $105 \pm 8$ & $1 I I \pm 9$ & 0.049 & $105 \pm 11$ & $108 \pm 6$ & 0.321 & $110 \pm 9$ & $106 \pm 9$ & 0.185 \\
\hline WHR & $0.83 \pm 0.08$ & $0.9 I \pm 0.07$ & 0.003 & $0.84 \pm 0.07$ & $0.97 \pm 0.06$ & $<\mathbf{0 . 0 0 1}$ & $0.83 \pm 0.08$ & $0.97 \pm 0.05$ & $<0.001$ \\
\hline $\begin{array}{l}\text { Number (percentage) of patients } \\
\text { with hypertension }\end{array}$ & $7(30.4)$ & $14(5 \mid .8)$ & 0.214 & $33(55.9)$ & $35(63.6)$ & 0.448 & $38(73.1)$ & $33(82.5)$ & 0.289 \\
\hline $\mathrm{SBP}(\mathrm{mmHg})$ & $122 \pm 14$ & $132 \pm 14$ & 0.020 & $133 \pm 17$ & $136 \pm 15$ & 0.433 & $138 \pm 22$ & $136 \pm 17$ & 0.575 \\
\hline $\mathrm{DBP}(\mathrm{mmHg})$ & $81 \pm 12$ & $75 \pm 10$ & 0.045 & $78 \pm 10$ & $77 \pm 10$ & 0.558 & $75 \pm 11$ & $74 \pm 11$ & 0.649 \\
\hline MAP (mmHg) & $95 \pm 12$ & $94 \pm 11$ & 0.734 & $96 \pm 11$ & $96 \pm 11$ & 0.974 & $96 \pm 13$ & $94 \pm 11$ & 0.573 \\
\hline $\mathrm{PP}(\mathrm{mmHg})$ & $4 I \pm 8$ & $57 \pm 8$ & $<\mathbf{0 . 0 0 1}$ & $56 \pm 13$ & $59 \pm 11$ & 0.124 & $64 \pm 16$ & $62 \pm 15$ & 0.694 \\
\hline $\mathrm{HR}(/ \mathrm{min})$ & $75 \pm 10$ & $72 \pm 9$ & 0.393 & $73 \pm 10$ & $69 \pm 8$ & 0.010 & $68 \pm 10$ & $68 \pm 10$ & 0.959 \\
\hline $\begin{array}{l}\text { Number (percentage) of patients } \\
\text { with type } 2 \text { diabetes }\end{array}$ & $2(8.7)$ & $5(18.5)$ & 0.416 & $20(33.9)$ & $29(52.7)$ & 0.259 & I8 (34.6) & $16(40.0)$ & 0.665 \\
\hline Glucose level $^{\mathrm{a}}(\mathrm{mg} / \mathrm{dL})$ & $92 \pm 9$ & $94 \pm 12$ & 0.591 & $103 \pm 32$ & $107 \pm 18$ & 0.625 & $102 \pm 12$ & $107 \pm 37$ & 0.528 \\
\hline $\begin{array}{l}\text { Number (percentage) of patients } \\
\text { with dyslipidemia }\end{array}$ & II (47.8) & $22(81.5)$ & 0.842 & $44(74.6)$ & $42(76.4)$ & 0.536 & $48(92.3)$ & $28(70.0)$ & 0.011 \\
\hline $\begin{array}{l}\text { Number (percentage) of patients } \\
\text { with treated dyslipidemia }\end{array}$ & $0(0.0)$ & $6(22.2)$ & 0.025 & $3(5.1)$ & $4(7.3)$ & 0.710 & $13(25.0)$ & $5(12.5)$ & 0.186 \\
\hline TC $_{\text {level }}{ }^{\mathrm{a}}(\mathrm{mg} / \mathrm{dL})$ & $214 \pm 36$ & $220 \pm 42$ & 0.631 & $225 \pm 41$ & $212 \pm 39$ & 0.076 & $23 I \pm 48$ & $210 \pm 32$ & 0.025 \\
\hline LDL cholesterol level ${ }^{\mathrm{a}}(\mathrm{mg} / \mathrm{dL})$ & $120 \pm 34$ & $137 \pm 38$ & 0.130 & $131 \pm 38$ & $128 \pm 37$ & 0.718 & $|35 \pm 5|$ & $126 \pm 27$ & 0.350 \\
\hline HDL cholesterol levela $(\mathrm{mg} / \mathrm{dL})$ & $64 \pm 24$ & $48 \pm 15$ & 0.007 & $54 \pm 15$ & $48 \pm 9$ & 0.016 & $62 \pm 16$ & $52 \pm 12$ & 0.003 \\
\hline TG level $^{\mathrm{a}}(\mathrm{mg} / \mathrm{dL})$ & $149 \pm 112$ & $161 \pm 72$ & 0.654 & $|5| \pm 77$ & $165 \pm 126$ & 0.528 & $149 \pm 60$ & $148 \pm 1 \mid 7$ & 0.953 \\
\hline Number (percentage) of smokers & II (47.8) & $15(55.6)$ & 0.794 & $23(39.0)$ & $21(38.2)$ & 0.917 & II (2I.2) & $13(32.5)$ & 0.323 \\
\hline CRP level (mg/L) & $3.30 \pm 5.74$ & $1.36 \pm 1.17$ & 0.362 & $1.58 \pm 1.43$ & $3.57 \pm 6.96$ & 0.260 & $3.1 I \pm 2.4 I$ & $2.60 \pm 2.26$ & 0.546 \\
\hline $\begin{array}{l}\text { Number (percentage) of patients } \\
\text { with metabolic syndrome }\end{array}$ & $8(34.8)$ & $14(5 \mid .8)$ & 0.354 & $27(45.8)$ & $24(43.6)$ & 0.968 & $31(59.6)$ & $19(47.5)$ & 0.344 \\
\hline LV ejection fraction \% & $70.4 \pm 4.9$ & $65.0 \pm 7.3$ & 0.010 & $70.1 \pm 6.0$ & $69.6 \pm 6.8$ & 0.695 & $69.6 \pm 8.5$ & $70.2 \pm 7.4$ & 0.758 \\
\hline
\end{tabular}

Notes: aMorning fasting serum concentration. Data presented as mean \pm SD or $n$ (\%) parameter values. Data in bold indicates statistical significance.

Abbreviations: F, females; M, males; BMI, body mass index; WHR, waist-to-hip ratio; SBP, systolic blood pressure; DBP, diastolic blood pressure; MAP, mean arterial pressure; PP, pulse pressure; HR, heart rate; TC, total cholesterol; LDL, low-density lipoprotein; HDL, high-density lipoprotein; TG, triglycerides; CRP, C-reactive protein; LV, left ventricle. 
Table 3 CIMT in male and female patients

\begin{tabular}{|c|c|c|c|}
\hline & \multicolumn{2}{|c|}{ All participants $(\mathrm{N}=\mathbf{2 5 6})$} & \multirow{2}{*}{$\frac{P \text {-value }}{F \text { vs } M}$} \\
\hline & Females $(n=134)$ & Males $(n=122)$ & \\
\hline CIMT & $0.54(0.5 \mathrm{I}-0.57)$ & $0.60(0.57-0.68)$ & $P=0.011$ \\
\hline Group I (<45 years) & $0.48(0.45-0.53)$ & $0.48(0.45-0.54)$ & $P=0.86 \mathrm{I}$ \\
\hline Group 2 (45-60 years) & $0.5 \mathrm{I}(0.5 \mathrm{I}-0.58)$ & $0.63(0.56-0.70)$ & $P=0.005$ \\
\hline Group 3 (>60 years) & $0.63(0.56-0.7 I)$ & $0.72(0.68-0.77)$ & $P=0.020$ \\
\hline$\Delta_{2-1}=$ group $2-$ group I & +0.03 & +0.15 & \\
\hline Group 2 vs group I & $P=0.013$ & $\mathbf{P}<0.00$ I & \\
\hline$\Delta_{3-2}=$ group $3-$ group 2 & +0.12 & +0.09 & \\
\hline Group 3 vs group 2 & $P=0.001$ & $P=0.005$ & \\
\hline$\Delta_{3-1}=$ group $3-$ group I & +0.15 & +0.24 & \\
\hline Group 3 vs group I & $\mathbf{P}<0.00 \mathrm{I}$ & $\mathbf{P}<\mathbf{0 . 0 0 I}$ & \\
\hline
\end{tabular}

Notes: $\Delta_{2-1}$, difference between age groups 2 and I; $\Delta_{3-2}$, difference between age groups 3 and $2 ; \Delta_{3-1}$, difference between age groups 3 and I. Data presented as median ( $95 \%$ confidence interval). Data in bold indicates statistical significance.

Abbreviations: F, females; M, males; CIMT, carotid intima-media thickness; BMI, body mass index.

values than women (age group 2: $0.51 \mathrm{~mm}$ for women vs $0.63 \mathrm{~mm}$ for men, $P=0.005$; age group $3: 0.63 \mathrm{~mm}$ for women vs $0.72 \mathrm{~mm}$ for men, $P=0.020$ ). CIMT increased with age in both subgroups (women: $\Delta$ CIMT $_{3-1}=0.15 \mathrm{~mm}, P<0.001$; men: $\left.\Delta \mathrm{CIMT}_{3-1}=0.24 \mathrm{~mm}, P<0.001\right)$, with male patients showing a larger increase in median CIMT in age group 2 than female participants (women: $\triangle \mathrm{CIMT}_{2-1}=0.03 \mathrm{~mm}$, $P=0.013$; men: $\left.\Delta \mathrm{CIMT}_{2-1}=0.15 \mathrm{~mm}, P<0.001\right)$.

In summary, CIMT in the entire female subgroup was significantly lower than in the entire male subgroup, while analysis of separate age groups revealed that the difference in CIMT between the sexes became significant after the age of 45 years.

\section{Correlations between CIMT and age}

Age was strongly correlated with CIMT measurements in both sexes (Figure 2). In all participants, age showed a

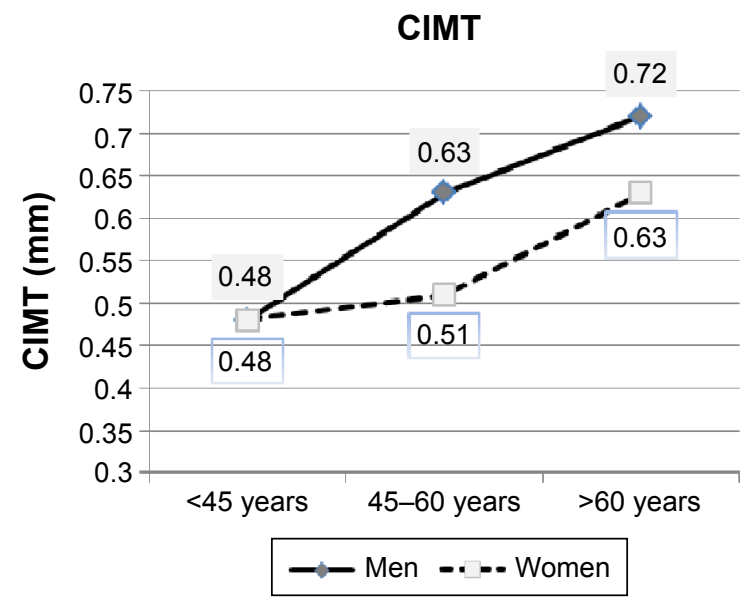

Figure I CIMT (median) changes with age in female and male patients. Abbreviation: CIMT, carotid intima-media thickness. positive correlation with CIMT ( $r=0.516, P<0.001)$. Similar correlations between CIMT and age were seen in separate analyses for the sex subgroups, with a positive correlation in both (women: $r=+0.465, P<0.001$; men: $r=+0.612$, $P<0.001)$.

\section{CIMT - single-factor analysis}

Factors affecting CIMT in the entire group were as follows: age ( $b=+0.008, P<0.0001)$, hypertension $(b=+0.059$, $P<0.01)$, PP $(b=+0.004, P<0.0001)$, type 2 diabetes ( $b=+0.095, P=0.0001)$, BMI $(b=+0.006, P<0.01)$, increased waist circumference $(b=+0.076, P<0.01)$, metabolic syndrome $(b=+0.044, P<0.05)$, and female sex $(b=-0.050$, $P<0.05$ ). Significant differences were observed between the sexes in terms of risk factor impact on CIMT. In men, only three factors significantly affected CIMT: age $(b=+0.009$, $P<0.0001)$, hypertension ( $b=+0.067, P<0.05)$, and type 2 diabetes $(b=+0.073, P<0.05)$. In women, apart from age $(b=+0.008, P<0.0001)$ and type 2 diabetes $(b=+0.111$, $P<0.01)$, significant factors were $\mathrm{PP}(b=+0.005, P<0.0001)$, BMI ( $b=+0.007, P<0.05$ ), increased waist circumference $(b=+0.092, P<0.01)$, and metabolic syndrome $(b=+0.071$, $P<0.05$ ). Linear regression analysis results for $\mathrm{CV}$ risk factors and CIMT in the entire group and in the male and female subgroups are given in Table 4.

\section{CIMT - multiple-factor analysis}

In the multiple regression analysis, independent CIMT determinants for the entire group were age $(b=+0.007, P<0.001)$ and BMI ( $b=+0.007, P=0.006$ ). For males, age was the only independent determinant of CIMT ( $b=+0.010, P<0.001)$. For females, these were PP $(b=+0.003, P=0.014)$, age $(b=+0.004$, $P=0.05)$, and increased waist circumference $(b=+0.068$, 


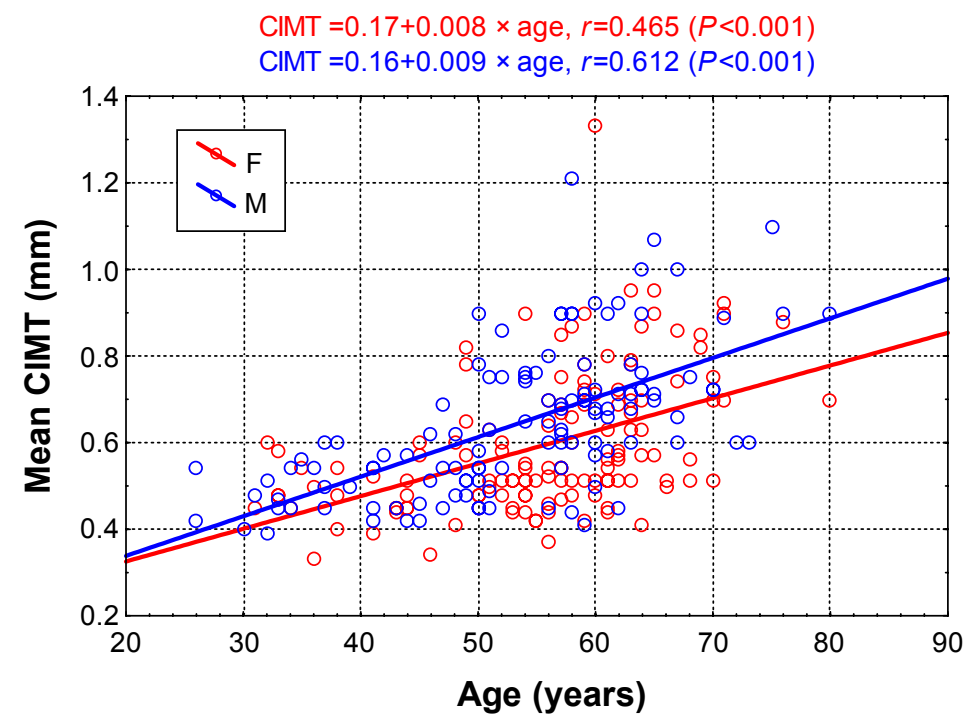

Figure 2 Correlation diagram of CIMT and age in male and female patients.

Abbreviations: CIMT, carotid intima-media thickness; F, females; $M$, males.

$P=0.048)$. Multiple regression analysis results for CIMT are given in Tables 5-7.

\section{Discussion}

\section{Age and CIMT}

In the present study group, CIMT values increased with age, both in women and in men. This finding is consistent with the literature data, including a large American study: Atherosclerosis Risk in Communities (ARIC).${ }^{14}$ In this study, CIMT values were lower in women than in men, with age subgroup analysis revealing that the difference in CIMT between the sexes becomes significant over the age of 45 years.

Changes occurring in women's vascular system in the perimenopausal period may be partially explained by the changing hormone profile at this stage of life. It is still debated which hormones contribute to the acceleration of atherosclerosis in women after menopause and whether it is more the question of decreasing estrogens or rather rising androgens. In the Multi-Ethnic Study of Atherosclerosis, comprising 1,947 postmenopausal women, elevated testosterone level and low sex hormone-binding globulin level were associated with increased CIMT, while no relationship between estradiol and CIMT was found. ${ }^{15}$ In a prospective analysis of 249 women in perimenopausal age (42-57 years) from the Study of Women's Health Across the Nation population, the decrease in estradiol levels and the concurrent increase in FSH level were independently correlated with an increase in carotid artery adventitial diameter, while the

Table 4 Linear regression analysis results for variables characterizing the participants (independent variables) and CIMT

\begin{tabular}{|c|c|c|c|}
\hline \multirow[t]{2}{*}{ Variable } & \multicolumn{3}{|c|}{ The slope coefficient $b$} \\
\hline & All 256 participants & I 34 female participants & I 22 male participants \\
\hline Age & $+0.008^{*}$ & $+0.008 *$ & $+0.009 *$ \\
\hline Sex (female) & $-0.050 * *$ & NA & NA \\
\hline Arterial hypertension & $+0.059 * * *$ & +0.048 & $+0.067 * *$ \\
\hline Mean arterial pressure & -0.001 & -0.0001 & +0.0001 \\
\hline Pulse pressure & $+0.004^{*}$ & $+0.005^{*}$ & +0.001 \\
\hline Diabetes mellitus & $+0.095^{*}$ & $+0.1 I I * * *$ & $+0.073 * *$ \\
\hline Dyslipidemia & -0.037 & -0.081 & +0.0001 \\
\hline Cigarette smoking & +0.014 & +0.028 & +0.050 \\
\hline Waist circumference $>$ normal & $+0.076 * * *$ & $+0.092 * * *$ & +0.049 \\
\hline Metabolic syndrome & $+0.044 * *$ & $+0.07 I^{* *}$ & +0.010 \\
\hline Heart rate & -0.002 & -0.002 & -0.001 \\
\hline BMI & $+0.006^{* * * *}$ & $+0.007^{* *}$ & +0.004 \\
\hline
\end{tabular}

Notes: $* P<0.001, * * P<0.05, * * * P<0.01$. Data in bold indicates statistical significance.

Abbreviations: CIMT, carotid intima-media thickness; BMI, body mass index; NA, not applicable. 
Table 5 Multiple regression analysis results for variables characterizing the 256 participants (independent variables) and CIMT

\begin{tabular}{|c|c|c|c|c|c|c|}
\hline & $\beta$ & $\mathbf{S E}_{\beta}$ & $b$ & $\mathbf{S E}_{b}$ & $P$-value & $\operatorname{VIF}(\beta)$ \\
\hline Intercept $b_{0}$ & NA & NA & -0.03 & 0.09 & 0.750 & NA \\
\hline Age & +0.497 & 0.068 & +0.007 & 0.001 & $<0.00 \mathrm{I}$ & 1.38 \\
\hline BMI & +0.195 & $0.07 I$ & +0.007 & 0.003 & 0.006 & 1.50 \\
\hline Metabolic syndrome & -0.128 & 0.073 & -0.031 & 0.024 & 0.062 & 1.40 \\
\hline Female & -0.117 & 0.062 & -0.038 & 0.020 & 0.058 & 1.13 \\
\hline PP & +0.109 & 0.069 & +0.001 & 0.001 & 0.117 & 1.35 \\
\hline Diabetes mellitus & +0.098 & 0.065 & +0.032 & 0.021 & 0.136 & 1.25 \\
\hline $\mathrm{HT}$ & +0.076 & 0.066 & +0.025 & 0.022 & 0.251 & 1.20 \\
\hline HR & -0.032 & 0.063 & -0.001 & 0.001 & 0.609 & 1.14 \\
\hline
\end{tabular}

Notes: CIMT $=-0.03+0.007-$ age $+0.007-$ BMI. $R^{2}=0.341$. Data in bold indicates statistical significance.

Abbreviations: CIMT, carotid intima-media thickness; SE, standard error; BMI, body mass index; PP, pulse pressure; HT, hypertension; HR, heart rate; NA, not applicable; VIF, variance inflation factor.

decrease in sex hormone-binding globulin observed at that time was independently correlated with CIMT increase. ${ }^{16}$ It is also noteworthy that the interaction between sex hormone levels and the development of vascular changes (including CIMT increase) is complex and involves various mechanisms, for example, insulin resistance, high blood pressure, and changes in lipid profile. ${ }^{17-19}$

As stated earlier, in the present study group, the difference in CIMT between the sexes became significant over the age of 45 years. Interesting observations on CIMT trends with age were provided by a German study on 4,814 healthy subjects aged 35-74 years. Women had lower CIMT values than men in all age groups, except for the oldest one ( $\sim 74$ years), where the difference between the sexes in terms of CIMT became insignificant. This can be explained by "survival bias" - in this case, earlier death of elderly men with higher CIMT values (entailing a higher risk of cardiovascular events) and, therefore, longer survival of men with lower CIMT. ${ }^{20}$

\section{Blood pressure and CIMT}

Cross-sectional studies showed a correlation between hypertension and increased CIMT in both sexes, in various populations. ${ }^{20,21}$ The ARIC study demonstrated that increased
SBP and DBP values were linked to higher CIMT in both females and males. ${ }^{22}$

In the present study group, similar results were obtained: SBP, DBP, and PP were correlated with CIMT in the entire group and in the female subgroup, but not in the male subgroup. The correlation between PP and CIMT in multiple regression analysis for females is an interesting observation from this study.

Recently, there has been growing interest in differences between the sexes in terms of age-related changes in two components of the blood pressure curve: the steady component, expressed by mean arterial pressure, and the pulsatile component, reflected by PP. ${ }^{23}$ It has been pointed out that in women (more clearly than in men), the pulsatile component of blood pressure - expressed by PP and largely dependent on arterial stiffness - increases with age compared to the steady component, which is expressed by mean arterial pressure and is mainly dependent on peripheral resistance. High PP may exacerbate shear stress, leading thus to endothelial dysfunction and acceleration of atherosclerosis.

In a cross-sectional study of a Spanish population, which included 3,161 patients with CV risk factors, PP proved to be an independent predictor of CIMT and, contrary to the present study group, both women and men were affected. ${ }^{24}$ In the

Table 6 Multiple regression analysis results for variables characterizing the I34 female participants (independent variables) and CIMT

\begin{tabular}{lllllll}
\hline & $\beta$ & $\mathbf{S E}_{\beta}$ & $\mathbf{b}$ & $\mathbf{S E}_{\mathbf{b}}$ & $\boldsymbol{P}$-value & VIF $(\beta)$ \\
\hline Intercept $b_{0}$ & $\mathrm{NA}$ & $\mathrm{NA}$ & +0.16 & 0.08 & $0.05 \mathrm{I}$ & $\mathrm{NA}$ \\
$\mathrm{PP}$ & $+\mathbf{0 . 3 1 7}$ & $\mathbf{0 . 1 2 5}$ & $+\mathbf{0 . 0 0 3}$ & $\mathbf{0 . 0 0 1}$ & $\mathbf{0 . 0 1 4}$ & $\mathbf{1 . 5 5}$ \\
Age & $+\mathbf{0 . 2 4 2}$ & $\mathbf{0 . 1 2 6}$ & $+\mathbf{0 . 0 0 4}$ & $\mathbf{0 . 0 0 2}$ & $\mathbf{0 . 0 5 0}$ & $\mathbf{1 . 5 2}$ \\
Waist circumference $>$ normal & $+\mathbf{0 . 2 0 7}$ & $\mathbf{0 . 1 0 3}$ & $+\mathbf{0 . 0 6 8}$ & $\mathbf{0 . 0 3 4}$ & $\mathbf{0 . 0 4 8}$ & $\mathbf{1 . 0 7}$ \\
Diabetes mellitus & +0.079 & 0.110 & +0.031 & 0.042 & 0.472 & 1.28 \\
Metabolic syndrome & +0.006 & 0.150 & +0.001 & 0.068 & 0.845 & 1.42 \\
BMI & -0.014 & 0.156 & -0.001 & 0.006 & 0.930 & 1.51 \\
\hline
\end{tabular}

Notes: CIMT $=0.16+0.003-\mathrm{PP}+0.004-$ age $+0.068-$ waist circumference $>$ normal. $R^{2}=0.350$. Data in bold indicates statistical significance.

Abbreviations: CIMT, carotid intima-media thickness; SE, standard error; PP, pulse pressure; BMI, body mass index; NA, not applicable; VIF, variance inflation factor. 
Table 7 Multiple regression analysis results for variables characterizing the 122 males (independent variables) and CIMT

\begin{tabular}{lllllll}
\hline & $\boldsymbol{\beta}$ & $\mathbf{S E}_{\beta}$ & $\boldsymbol{b}$ & $\mathbf{S E}_{\boldsymbol{b}}$ & $\boldsymbol{P}$-value & VIF $(\boldsymbol{\beta})$ \\
\hline Intercept $b_{0}$ & $\mathrm{NA}$ & $\mathrm{NA}$ & $+\mathbf{0 . 1 3}$ & $\mathbf{0 . 0 6}$ & $\mathbf{0 . 0 4 5}$ & $\mathrm{NA}$ \\
Age & $+\mathbf{0 . 6 6 9}$ & $\mathbf{0 . 0 7 7}$ & $+\mathbf{0 . 0 1 0}$ & $\mathbf{0 . 0 0 1}$ & $<\mathbf{0 . 0 0 1}$ & $\mathbf{1 . 5 2}$ \\
$\mathrm{HT}$ & +0.048 & 0.082 & +0.016 & 0.028 & $0.56 \mathrm{I}$ & 1.51 \\
Diabetes mellitus & +0.028 & 0.083 & +0.009 & 0.027 & 0.736 & 1.28
\end{tabular}

Notes: $\mathrm{CIMT}=+0.13+0.010-$ age. $R^{2}=0.448$. Data in bold indicates statistical significance.

Abbreviations: CIMT, carotid intima-media thickness; SE, standard error; HT, hypertension; NA, not applicable; VIF, variance inflation factor.

ELSA-Brazil Cohort (9,792 subjects), PP had a significant contribution to the prediction of CIMT. ${ }^{9}$ A study on a French population also revealed that the correlation between PP and CIMT was bidirectional: initially determined PP is a predictor of CIMT and initially determined CIMT is a predictor of PP. ${ }^{25}$ The question whether it is high PP that contributes to the CIMT increase or vice versa remains open.

\section{Diabetes and CIMT}

Linear regression analysis in the present population revealed a significant correlation between type 2 diabetes and CIMT in the entire study group and in the sex subgroups analyzed separately. However, diabetes did not prove to be an independent predictor of CIMT in multiple regression analysis.

Links between type 2 diabetes and CIMT are well documented in the literature. Type 2 diabetes was a predictor for increased CIMT in various groups: among Finnish males with CV risk factors ${ }^{26}$ and in an American population in the ARIC study. ${ }^{22}$ In the German Gutenberg Heart Study, type 2 diabetes significantly affected CIMT in males, but not in females. ${ }^{20}$

In this study, fasting glucose was not correlated with CIMT. On the one hand, patients with type 2 diabetes in this study group were treated with hypoglycemics, which might have distorted any correlation between glucose levels and CIMT. On the other hand, literature reports on the relationship between fasting glucose and CIMT are contradictory: no correlations were found between the two parameters, for example, in Chinese groups of patients with normal glycemia and with impaired fasting glucose tolerance ${ }^{27}$ and in a German group of patients with carbohydrate metabolism disorders. ${ }^{28}$ In summary, while the correlation between diabetes and CIMT seems indisputable, the relationship between fasting glucose levels and CIMT remains uncertain.

\section{Lipids and CIMT}

Numerous prospective studies - including the large ARIC study - prove the predictive value of LDL cholesterol for CIMT increases and the protective prognostic value of HDL cholesterol. ${ }^{21,29}$ Also Santos et $\mathrm{al}^{9}$ in ELSA-Brasil
Cohort showed that LDL/HDL ratio contributed to increased CIMT.

Interesting observations were made in a study of 1,648 Japanese patients with type 2 diabetes, in whom vascular stiffness (using baPWV [brachial ankle pulse wave velocity]) and CIMT were assessed. LDL and HDL cholesterol were independent determinants of CIMT, while no significant correlation with baPWV was found. ${ }^{30}$

In the present study group, lipid abnormalities were not found to be independent determinants of CIMT. This observation is consistent with the results of the study by Rundek et al, ${ }^{8}$ in which the association between LDL cholesterol and CIMT was marginal, whereas HDL cholesterol, total cholesterol, and triglycerides exerted no significant effect on CIMT.

\section{Obesity and CIMT}

The correlation between obesity parameters - BMI and increased waist circumference - and CIMT is well documented in the literature. BMI, together with age and waistto-height ratio, was an independent predictor of CIMT in a population of healthy Irish subjects. ${ }^{31}$ Similar results were obtained in the large Progetto ATENA study, including 5,062 middle-aged Italian women, where BMI and WHR were independent CIMT predictors. ${ }^{32}$ What is worth noting, in the ELSA-Brasil Cohort, is that the neck circumference was proved to be the adiposity marker strongly associated with CIMT, especially in comparison to traditional adiposity markers such as WHR. ${ }^{9}$

In this study, significant correlations between waist circumference, BMI, and CIMT were found and were especially marked in females. In the entire study group, BMI was an independent predictor of CIMT. In females, waist circumference was an independent CIMT determinant, while in male subjects, no significant correlation was found between CIMT and increased waist circumference or BMI.

The stronger impact of obesity on CIMT in females observed in this study is corroborated in the literature. In the Italian SardiNIA study, BMI and increased waist circumference were correlated with increased CIMT in both sexes, but the correlation was stronger in women. ${ }^{33}$ 


\section{Nicotine and CIMT}

This study did not reveal any significant correlation between nicotine addiction and CIMT. However, such correlation was reported in many studies, including the large prospective study of an American population, ARIC, 22,34 and the Bogalusa Heart Study performed in an American population of young adults. ${ }^{35}$ The Bogalusa Heart Study also demonstrated that active smokers had higher CIMT values than nonsmokers, despite having lower BMI and waist circumference values and lower fasting glucose levels. ${ }^{36}$

\section{Metabolic syndrome and CIMT}

In this study, metabolic syndrome was significantly correlated with CIMT in the entire group and in the female subgroup in single-factor analysis, but the correlation became insignificant in multiple-factor analysis. However, it is of great importance that two features of metabolic syndrome - increased waist circumference and a hypertensive parameter (PP) - remained significant in multiple-factor analysis in the female subgroup. Notably, no correlation was found between metabolic syndrome and CIMT in the male subgroup.

Literature data also include observations indicating a stronger impact of metabolic syndrome on CIMT in women than in men. In a Taiwanese study, metabolic syndrome as defined by Adult Treatment Panel III was significantly correlated with higher CIMT in women, but not in men. ${ }^{37}$

Interesting results were reported in a study by Olszanecka et $\mathrm{al}^{38}$ on a population similar to that in this study: 152 perimenopausal Polish women (mean age: 51 years), newly diagnosed with arterial hypertension. In that population, independent predictors of increased CIMT were age, SBP, and metabolic syndrome as defined by International Diabetes Federation. In a similar way to the present results, the key metabolic syndrome component that affected CIMT - aside from blood pressure parameters - was increased waist circumference, the marker of abdominal obesity. In recent years, increased attention has been paid to the role of adipose tissue distribution and the stronger impact of abdominal stored fat on atherosclerosis progression. ${ }^{39}$ Therefore, CVD risk stratification should incorporate not only BMI but also waist circumference.

Literature data indicate that the impact of metabolic syndrome on CIMT is more marked in women than in men. This can be explained by the fact that in women, metabolic syndrome contributes to a premature cessation of the protective effects of estrogens in the cardiovascular system.

\section{In summary}

The influence of traditional CV risk factors on CIMT is still unclear. The results of recently published studies indicate that the impact of traditional CV risk factors on CIMT is marginal, which was also observed in our study group. In our study, age and BMI were the only factors affecting CIMT in the whole group in the multiple-factor analysis. These observations may suggest that CIMT is not a direct marker of atherosclerosis but rather of adaptive changes that occur with age in the arterial wall and include the hypertrophy of the media in response to high blood pressure. ${ }^{8}$ However, this issue requires further research.

\section{Strengths and limitations}

The strength of our study is the analysis of the impact of $\mathrm{CV}$ risk factors on CIMT, performed separately in men and women in different age groups.

Limitations of the study: our analysis is cross-sectional and includes only Caucasian subjects - therefore, its results cannot be generalized to other populations. We analyzed patients at the initial stages of atherosclerosis and excluded those with carotid plaques. We did not measure the sex hormone serum levels. Conclusion must be made with caution because results of this study might be influenced by small sample size.

\section{Conclusion}

CIMT values are lower in women than in men, which is most pronounced over the age of 45 years. There are sexrelated differences in the profile of $\mathrm{CV}$ risk factors affecting CIMT: in males, CIMT is mostly determined by age, while in females: by age, PP, and increased waist circumference. This paper demonstrates the necessity of separate analyses for the sex subgroups. The identification of separate profiles of risk factors affecting CIMT in men and women may have significant implications for developing cardiovascular disease prevention strategies.

\section{Disclosure}

The authors report no conflicts of interest in this work.

\section{References}

1. Hodis HN, Mack WJ, LaBree L, et al. The role of carotid arterial intimamedia thickness in predicting clinical coronary events. Ann Intern Med 1998; 128:262-269.

2. Bots ML, Hoes AW, Koudstaal PJ, Hofman A, Grobbee DE. Common carotid intima-media thickness and risk of stroke and myocardial infarction: the Rotterdam study. Circulation. 1997;96(5):1432-1437.

3. Chambless LE, Folsom AR, Clegg LX, et al. Carotid wall thickness is predictive of incident clinical stroke: the atherosclerosis risk in communities (ARIC) study. Am J Epidemiol. 2000;151(5):478-487. 
4. Lorenz MW, von Kegler S, Steinmetz H, Markus HS, Sitzer M. Carotid intima-media thickening indicates a higher vascular risk across a wide age range: prospective data from the carotid atherosclerosis progression study (CAPS). Stroke. 2006;37(1):87-92.

5. Finn AV, Kolodgie FD, Virmani R. Correlation between carotid intimal/ medial thickness and atherosclerosis: a point of view from pathology. Arterioscler Thromb Vasc Biol. 2010;30(2):177-181.

6. Fraser AG, Kyaw Y, Kozakova M, Palombo C. Ultrasonic imaging of the carotid arteries, from intima-media thickness to histological markers for plaque vulnerability: what do we know? Dialog Cardiovasc Med. 2013;18:87-98.

7. Vlachopoulos CH, Xaplanteris P, Aboyans V, et al. The role of vascular biomarkers for primary and secondary prevention. A position paper from European society of cardiology working group on peripheral circulation endorsed by the association for research into arterial structure and physiology (ARTERY) society. Atherosclerosis. 2015;241:507-532.

8. Rundek T, Blanton SH, Bartels S, et al. Traditional risk factors are not major contributors to the variance in carotid intima-media thickness. Stroke. 2013;44(8):2101-2108.

9. Santos IS, Alencar AP, Rundek T, et al. Low impact of traditional risk factors on carotid intima-media thickness: the ELSA-Brasil cohort. Arterioscler Thromb Vasc Biol. 2015;35(9):2054-2059.

10. Yusuf S, Hawken S, Ounpuu S, et al; INTERHEART Study Investigators. Effect of potentially modifiable risk factors associated with myocardial infarction in 52 countries (the INTERHEART study): case-control study. Lancet. 2004;364(9438):937-952.

11. Mancia G, Fagard R, Narkiewicz K, et al. 2013 ESH/ESC guidelines for the management of arterial hypertension: the task force for the management of arterial hypertension of the European society of hypertension (ESH) and of the European society of cardiology (ESC). Eur Heart J. 2013;34(28):2159-2219.

12. Grundy SM, Cleeman JI, Daniels SR, et al; American Heart Association; National Heart, Lung, and Blood Institute. Diagnosis and management of the metabolic syndrome: an American Heart Association/National Heart, Lung, and Blood Institute Scientific Statement. Circulation. 2005; 112(17):2735-2752.

13. Touboul PJ, Hennerici MG, Meairs S, et al. Mannheim carotid intimamedia thickness and plaque consensus (2004-2006-2011). An update on behalf of the advisory board of the $3 \mathrm{rd}$, 4th and 5th watching the risk symposia, at the 13th, 15th and 20th European Stroke Conferences, Mannheim, Germany, 2004, Brussels, Belgium, 2006, and Hamburg, Germany, 2011. Cerebrovasc Dis. 2012;34(4):290-296.

14. Howard G, Sharrett AR, Heiss G, et al. Carotid artery intimal-medial thickness distribution in general populations as evaluated by B-mode ultrasound. ARIC Investigators. Stroke. 1993;24(9):1297-1304.

15. Ouyang P, Vaidya D, Dobs A, et al. Sex hormone levels and subclinical atherosclerosis in postmenopausal women: the multi-ethnic study of atherosclerosis. Atherosclerosis. 2009;204(1):255-261.

16. El Khoudary SR, Wildman RP, Matthews K, Thurston RC, Bromberger JT, Sutton-Tyrrell K. Endogenous sex hormones impact the progression of subclinical atherosclerosis in women during the menopausal transition. Atherosclerosis. 2012;225(1):180-186.

17. Golden SH, Dobs AS, Vaidya D, et al. Endogenous sex hormones and glucose tolerance status in postmenopausal women. J Clin Endocrinol Metab. 2007;92(4):1289-1295.

18. Wang L, Szklo M, Folsom AR, Cook NR, Gapstur SM, Ouyang P. Endogenous sex hormones, blood pressure change, and risk of hypertension in postmenopausal women: the multi-ethnic study of atherosclerosis. Atherosclerosis. 2012;224(1):228-234.

19. Polderman KH, Gooren LJ, Asscheman H, Bakker A, Heine RJ. Induction of insulin resistance by androgens and estrogens. J Clin Endocrinol Metab. 1994;79(1):265-271.

20. Sinning C, Wild PS, Echevarria FM, et al. Sex differences in early carotid atherosclerosis (from the community-based Gutenberg-heart study). Am J Cardiol. 2011;107(12):1841-1847.
21. Crouse JR, Goldbourt U, Evans G, et al. Risk factors and segmentspecific carotid arterial enlargement in the atherosclerosis risk in communities (ARIC) cohort. Stroke. 1996;27(1):69-75.

22. Dobs AS, Nieto FJ, Szklo M, Barnes R, Sharrett AR, Ko WJ. Risk factors for popliteal and carotid wall thicknesses in the atherosclerosis risk in communities (ARIC) study. Am J Epidemiol. 1999;150(10): 1055-1067.

23. Safar ME, Levy BI, Struijker-Boudier H. Current perspectives on arterial stiffness and pulse pressure in hypertension and cardiovascular diseases. Circulation. 2003;107(22):2864-2869.

24. Grau M, Subirana I, Agis D, et al. Carotid intima-media thickness in the Spanish population: reference ranges and association with cardiovascular risk factors. Rev Esp Cardiol (Engl Ed). 2012;65(12):1086-1093.

25. Zureik M, Touboul PJ, Bonithon-Kopp C, et al. Cross-sectional and 4-year longitudinal associations between brachial pulse pressure and common carotid intima-media thickness in a general population. The EVA study. Stroke. 1999;30(3):550-555.

26. Salonen R, Salonen JT. Determinants of carotid intima-media thickness: a population-based ultrasonography study in eastern Finnish men. J Intern Med. 1991;229(3):225-231.

27. Zhang YF, Hong J, Zhan WW, et al. Hyperglycaemia after glucose loading is a major predictor of preclinical atherosclerosis in nondiabetic subjects. Clin Endocrinol. 2006;64(2):153-157.

28. Hanefeld M, Temelkova-Kurktschiev T, Schaper F, Henkel E, Siegert G, Koehler C. Impaired fasting glucose is not a risk factor for atherosclerosis. Diabet Med. 1999;16(3):212-218.

29. Rosvall M, Persson M, Östling G, et al. Risk factors for the progression of carotid intima-media thickness over a 16-year follow-up period: the Malmö diet and cancer study. Atherosclerosis. 2015;239(2):615-621.

30. Takahara M, Katakami N, Osonoi T, et al. Different impacts of cardiovascular risk factors on arterial stiffness versus arterial wall thickness in Japanese patients with type 2 diabetes mellitus. J Atheroscler Thromb. 2015;22(9):971-980.

31. Maher V, O'Dowd M, Carey M, et al. Association of central obesity with early carotid intima-media thickening is independent of that from other risk factors. Int J Obes (Lond). 2009;33(1):136-143.

32. De Michele M, Panico S, Iannuzzi A, et al. Association of obesity and central fat distribution with carotid artery wall thickening in middleaged women. Stroke. 2002;33(12):2923-2928.

33. Scuteri A, Orru' M, Morrell CH, et al. Associations of large artery structure and function with adiposity: effects of age, gender, and hypertension. The SardiNIA study. Atherosclerosis. 2012;221(1):189-197.

34. Chambless LE, Folsom AR, Davis V, et al. Risk factors for progression of common carotid atherosclerosis: the atherosclerosis risk in communities study, 1987-1998. Am J Epidemiol. 2002;155(1):38-47.

35. Chen W, Srinivasan SR, Berenson GS. Differential impact of heart rate on arterial wall stiffness and thickness in young adults: the Bogalusa heart study. J Am Soc Hypertens. 2008;2(3):152-157.

36. Li S, Yun M, Fernandez C, et al. Cigarette smoking exacerbates the adverse effects of age and metabolic syndrome on subclinical atherosclerosis: the Bogalusa heart study. PLoS One. 2014;9(5):e96368.

37. Lin HF, Liu CK, Liao YC, Lin RT, Chen CS, Juo SH. The risk of the metabolic syndrome on carotid thickness and stiffness: sex and age specific effects. Atherosclerosis. 2010;210(1):155-159.

38. Olszanecka A, Dragan A, Kawecka-Jaszcz K, Czarnecka D. Influence of metabolic syndrome and its components on subclinical organ damage in hypertensive perimenopausal women. Adv Med Sci. 2014;59(2):232-239.

39. Lo J, Dolan SE, Kanter JR, et al. Effects of obesity, body composition, and adiponectin on carotid intima-media thickness in healthy women. J Clin Endocrinol Metab. 2006;91(5):1677-1682. 


\section{Publish your work in this journal}

Clinical Interventions in Aging is an international, peer-reviewed journal focusing on evidence-based reports on the value or lack thereof of treatments intended to prevent or delay the onset of maladaptive correlates of aging in human beings. This journal is indexed on PubMed Central, MedLine,

\section{Dovepress}

CAS, Scopus and the Elsevier Bibliographic databases. The manuscript management system is completely online and includes a very quick and fair peer-review system, which is all easy to use. Visit http://www.dovepress. $\mathrm{com} /$ testimonials.php to read real quotes from published authors. 